\title{
Transformation in Thermoactinomyces vulgaris
}

\author{
By D. A. HOPWOOD AND HELEN M. WRIGHT \\ John Innes Institute, Colney Lane, Norwich, NOR $70 F$ \\ (Accepted for publication I5 February 1972)
}

\begin{abstract}
SUMMARY
Genetic recombination occurs with a rather high frequency (up to $10^{-3}$ ) in mixed cultures of auxotrophic and streptomycin-resistant mutant derivatives of Thermoactinomyces vulgaris strain T9 growing on agar medium. It is shown that transformation by DNA is responsible for this recombination. Certain other newly isolated strains resemble T9 in being competent for transformation and are interfertile with each other and with T9. Some other strains are incompetent but can act as donors to the first set of strains. A fully synthetic minimal medium and conditions for efficient mutagenesis have been defined.
\end{abstract}

\section{INTRODUCTION}

We have already outlined briefly the discovery of genetic recombination in the thermophilic actinomycete Thermoactinomyces vulgaris (Hopwood \& Ferguson, 1970) and its characterization as a transformation process (Hopwood \& Wright, 1971). This paper describes the results of these studies in detail. It includes the formulation of a fully synthetic minimal medium for propagation of the organism and description of the isolation of auxotrophic mutants in good yield after heating the spores in vacuo as previously described for Bacillus subtilis by Chiasson \& Zamenhof (1966).

Our current interest in genetic analysis of this organism centres particularly on a study of the architecture of its endospores. These, as described in the accompanying paper (McVittie, Wildermuth \& Hopwood, I972), are polyhedral, the surface layer consisting of approximately equal numbers of pentagonal and hexagonal faces. We hope that the isolation and characterization of mutants with deviant spore architecture may give insight into the development of regular structure at this level of biological complexity.

At least two other applications of this genetic system suggest themselves. One is a genetic analysis of spore surface antigens in relation to the causation of Farmer's Lung; this organism is one of two thermophilic actinomycetes identified as causal agents of this allergic condition (Pepys et al. 1963). The second is a genetic analysis of the basis of thermophilic growth; this is, as far as we are aware, the first system of genetic recombination to be reported in a thermophilic bacterium, as attempts to demonstrate transformation in Bacillus stearothermophilus (Streips \& Welker, 1971) have so far been unsuccessful.

\section{METHODS}

Bacterial strains. Wild-type strain CUB76 of Thermoactinomyces vulgaris was kindly supplied by Dr T. Cross, University of Bradford. Other wild-types were isolated from soil samples as described by Hopwood \& Ferguson (1970). Most of the experiments concerned mutant and recombinant derivatives of one wild-type, T9, stock number 1227 ; these are listed in Table $\mathrm{I}$. Other wild-types and their mutant derivatives are referred to in the text. 
Table I. Characteristics of strains derived from wild-type T9

\begin{tabular}{|c|c|c|c|c|c|c|}
\hline \multirow[b]{2}{*}{ Strain } & \multicolumn{6}{|c|}{ Relevant phenotype } \\
\hline & nic-I & pro-I & str-I & thi-3 & trp-2 & ura- $r$ \\
\hline $1227^{*}$ & + & + & $\mathbf{S}$ & + & + & + \\
\hline 1250 & - & + & $\mathbf{S}$ & + & + & + \\
\hline $126 \mathrm{I}$ & - & + & $\mathbf{R}$ & - & + & + \\
\hline 1263 & + & + & $\mathrm{S}$ & + & + & - \\
\hline 1278 & + & + & $\mathrm{R}$ & - & + & - \\
\hline 1279 & - & + & $\mathbf{R}$ & + & + & - \\
\hline 1286 & + & + & $\mathrm{S}$ & - & + & + \\
\hline 1332 & - & - & $\mathbf{R}$ & - & + & + \\
\hline 1336 & + & + & $\mathrm{S}$ & + & - & + \\
\hline
\end{tabular}

Media. The basis of all media was Czapek-Dox medium of the following composition, per litre: sodium nitrate, $2 \mathrm{~g}$; potassium chloride, $0.5 \mathrm{~g}$; magnesium glycerophosphate, $0.5 \mathrm{~g}$; ferrous sulphate, $0.0 \mathrm{I} \mathrm{g}$; potassium sulphate, $0.35 \mathrm{~g}$; Oxoid agar no. 3, $12 \mathrm{~g}$. Sucrose was autoclaved separately as a $50 \%(\mathrm{w} / \mathrm{v})$ solution and added to the medium at a final concentration of $3 \%(\mathrm{w} / \mathrm{v})$.

Three media were prepared by addition of various supplements to the Czapek-Dox base. Minimal medium with casein hydrolysate (MMC) consisted of Czapek-Dox medium plus $0.6 \%$ (w/v) Bacto vitamin-free Casamino acids (Difco). This medium was used for the propagation of wild-type and amino acid (except tryptophan) requiring strains and, with addition of specific growth factors, for growing vitamin, pyrimidine, purine and tryptophan requiring strains; in the absence of particular growth-factor additions it was used as a selective medium for the recovery of recombinants lacking requirements for such growth factors.

Synthetic minimal medium (MMS) consisted of Czapek-Dox medium supplemented with L-alanine, L-arginine, L-aspartic acid, L-methionine, L-threonine and L-valine (I mM each) and spermidine $(0.0015 \%, \mathrm{v} / \mathrm{v})$. This medium was used, sometimes with specific growthfactor supplementation, for the selection of amino acid non-requiring recombinants from crosses involving amino acid markers, and for the detection of amino acid requiring mutants.

Complete medium (CM) consisted of MMC supplemented with L-tryptophan $(50 \mu \mathrm{g} / \mathrm{ml})$, thymine, guanine and uracil (Io $\mu \mathrm{g} / \mathrm{ml}$ each), nicotinamide, $p$-aminobenzoic acid, pantothenic acid, pyridoxin and thiamine ( $\mathrm{I} \mu \mathrm{g} / \mathrm{ml}$ each). Occasionally adenine ( $\mathrm{I} 0 \mu \mathrm{g} / \mathrm{ml}$ ) and riboflavin ( $\mathrm{I} \mu \mathrm{g} / \mathrm{ml}$ ) were added to $\mathrm{CM}$ when mutants requiring these growth factors were to be isolated and propagated; these additions were not made routinely since they tended to decrease the growth rate of non-requiring strains.

All growing cultures were incubated at 50 to $52{ }^{\circ} \mathrm{C}$.

Preparation of spore suspensions. Water (about Io $\mathrm{ml}$ ) was added to a sporulated culture, either on a slant or on a plate, and the surface of the culture was scraped with a loop to suspend the spores and fragments of mycelium. The suspension was agitated violently on a 'Whirlimixer' (Fisons Scientific Apparatus Ltd, Loughborough, Leicestershire) and filtered through cotton-wool, then centrifuged at $1000 \mathrm{~g}$ for ro min. The pellet was resuspended in water ( $\mathrm{I}$ to $2 \mathrm{ml}$ ) and agitated again to disperse the spores.

Isolation of mutants. The first auxotrophic mutants were isolated after exposure of spore suspensions in water to approximately $2000 \mathrm{ergs} / \mathrm{mm}^{2}$ ultraviolet light, plating on $\mathrm{CM}$ to yield 100 to 300 colonies per plate, and replication by means of velvet to MMC or, after 
the synthetic minimal medium had been devised, to MMS. Colonies failing to grow on the replicas, or growing weakly, were isolated to plates of CM, 20 per dish, and then rereplicated to MMC or MMS. Patches giving rise to weak growth or none on the replicas in this test were classified as auxotrophic mutants and their requirements were determined in the normal way. In later work, mutagenesis was effected by heating spores in vacuo according to the procedure devised by Chiasson \& Zamenhof (1966) for Bacillus subtilis. A spore suspension in water was centrifuged in a $100 \times 6 \mathrm{~mm}$ glass ampoule and, after the supernatant had been discarded, the ampoule was evacuated and sealed on an Edwards model 5 PS freeze-drier. The ampoule was heated by immersion for $\mathrm{I} 6 \mathrm{~min}$ in a beaker of stirred paraffin oil heated intermittently by a Bunsen flame. The temperature of the oil was set at a value between II 5 and I2I ${ }^{\circ} \mathrm{C}$ and varied by about $0.5{ }^{\circ} \mathrm{C}$ on either side of the chosen temperature in any particular experiment.

Crossing procedure. Crosses were performed by streaking spores of two parent strains together on slants of MMC supplemented by any further required growth factors, or on $\mathrm{CM}$, in $\mathrm{I} 50 \times 25 \mathrm{~mm}$ tubes. After incubation of the cultures for $\mathrm{I} 6$ to $48 \mathrm{~h}$, spore suspensions were prepared and plated $(0 . \mathrm{I} \mathrm{ml})$ on selective media consisting of MMC or MMS with various combinations of added growth factors, at appropriate dilutions. The plates were incubated for 20 to $48 \mathrm{~h}$ and samples of the recombinant colonies that arose were inoculated, 50 per dish, to plates of the same selective media. After incubation of these 'master plates' for $24 \mathrm{~h}$, they were replicated by velvet pads to media diagnostic for particular non-selected markers. In this way the phenotype of a sample of recombinants from each selective medium was determined after overnight incubation of the diagnostic plates.

Preparation of transforming DNA. The procedure was closely modelled on that of Marmur (196I). The organism was grown in a $2000 \mathrm{ml}$ Erlenmeyer flask containing $500 \mathrm{ml}$ of liquid MMC. The flask was inoculated with a dense suspension of spores and shaken rapidly on a New Brunswick Gyrotary Shaker at $50^{\circ} \mathrm{C}$ for 16 to $20 \mathrm{~h}$. The mycelium was harvested by centrifugation, suspended in about $200 \mathrm{ml}$ of tris-EDTA buffer (0.2 M-tris, O.I M-EDTA), $\mathrm{pH} 8$, recentrifuged and finally suspended in Io $\mathrm{ml}$ of the tris-EDTA buffer. Sometimes the mycelium was frozen and stored at this stage. Lysis was achieved by incubating at $37^{\circ} \mathrm{C}$ for $30 \mathrm{~min}$ with lysozyme (Sigma, Grade I) at I $\mathrm{mg} / \mathrm{ml}$ and then heating at $60^{\circ} \mathrm{C}$ for Io min with $\mathrm{I} \%(\mathrm{w} / \mathrm{v})$ sodium lauryl sulphate. One deproteinization (Marmur, I96I) with chloroformamyl alcohol was then performed, and the 'spooled' DNA produced by alcohol precipitation was redissolved in $10 \mathrm{ml}$ of standard saline-citrate solution. After incubation with $50 \mu \mathrm{g} / \mathrm{ml}$ pancreatic ribonuclease (Koch-Light Laboratories Ltd, Colnbrook, Buckinghamshire) for $30 \mathrm{~min}$ at $37^{\circ} \mathrm{C}$, a second deproteinization and alcohol precipitation was carried out and the crude DNA finally dissolved in $10 \mathrm{ml}$ of standard saline-citrate solution. The concentration of DNA, determined from the absorption at $260 \mathrm{~nm}$, was 0.5 to $2.0 \mathrm{mg} / \mathrm{ml}$. Typical absorption ratios at $260: 230: 280 \mathrm{~nm}$ were $\mathrm{I}: 0 \cdot 6: 0 \cdot 5$. The guanine + cytosine (GC) content of the DNA was kindly determined by Dr I. Gibson, School of Biological Sciences, University of East Anglia. Measurements of its buoyant density and melting temperature gave a GC content of approximately $5 \mathrm{I} \%$. This confirms the finding of Silvestri (1970) that Thermoactinomyces vulgaris DNA has a much lower GC content than members of most other genera of actinomycetes.

Transformation procedure. A o.I $\mathrm{ml}$ sample of a spore suspension of a recipient strain was spread on a plate of non-selective medium containing streptomycin (either MMC with any additional required growth factors or CM). A $0.2 \mathrm{ml}$ sample of DNA solution was then spread over the recipient culture, either immediately or after various periods of prior incubation of the culture. The culture was incubated for a total period of 20 to $40 \mathrm{~h}$. before 

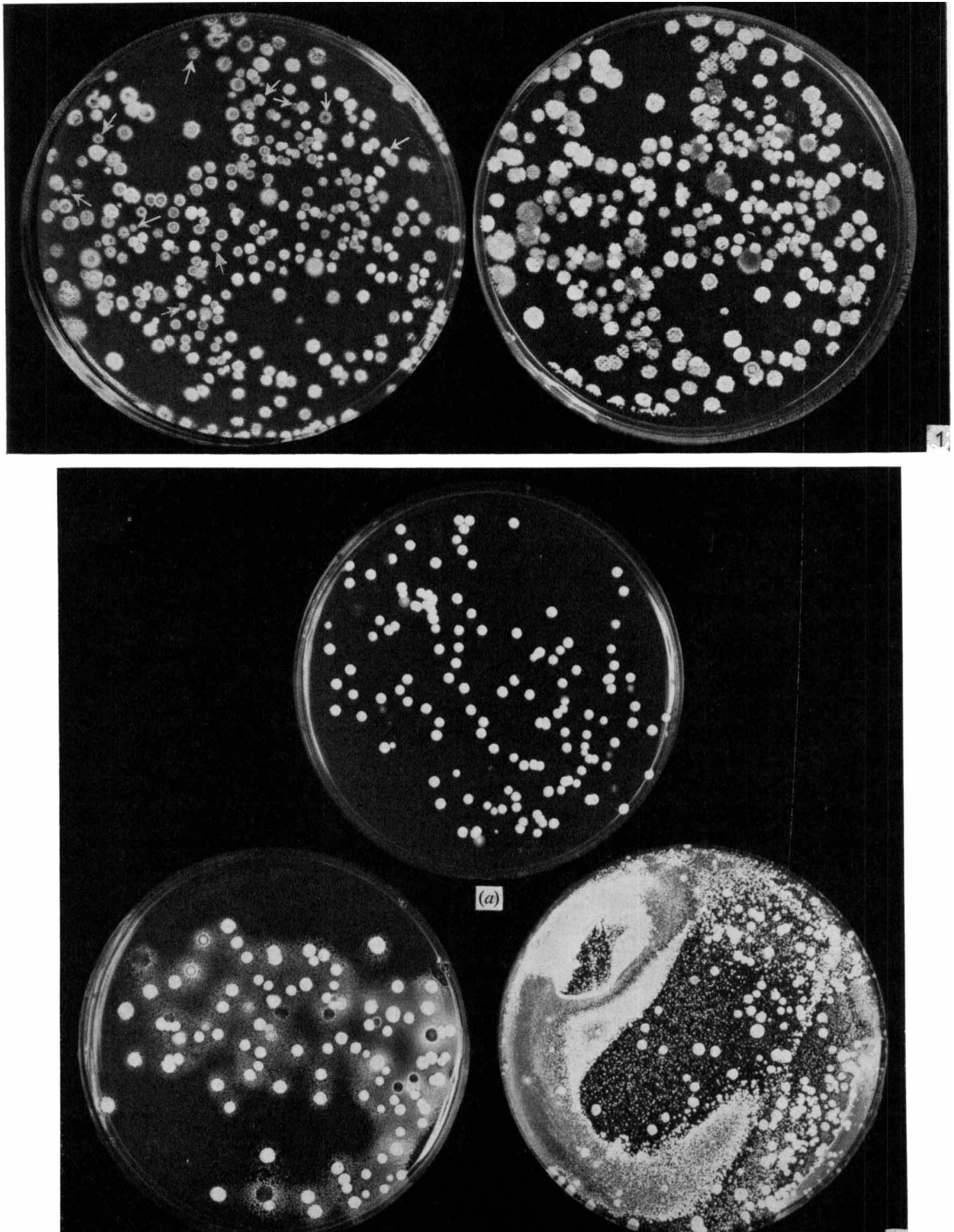

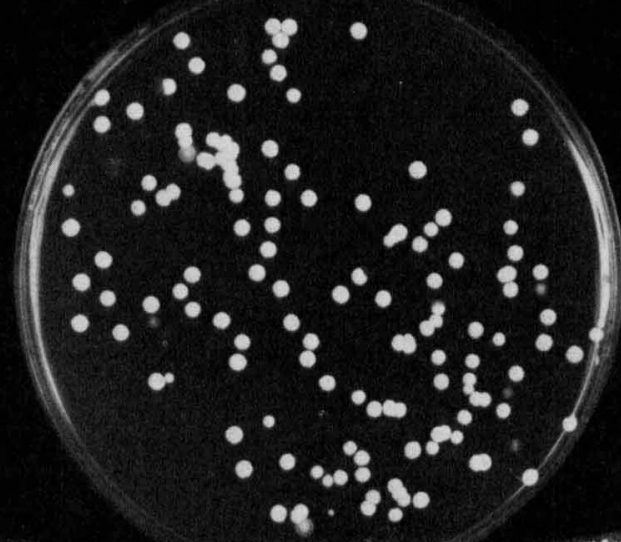

(a)

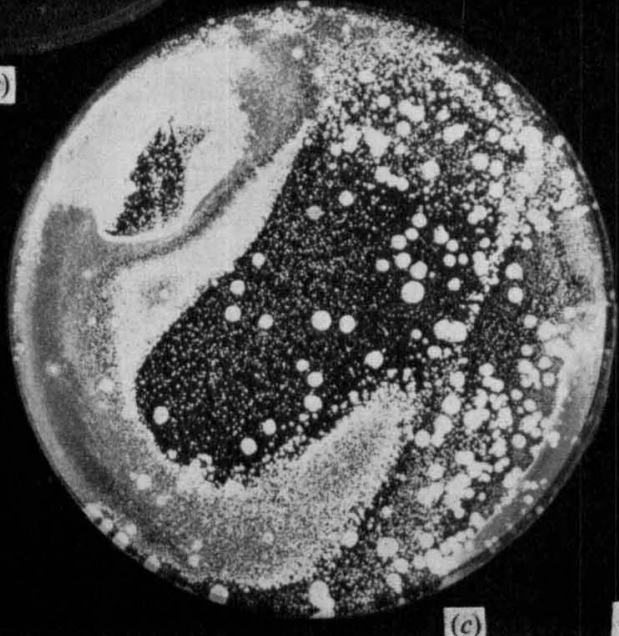


spores were harvested and plated in the same way as those from a cross. In the experiments on the effect of DNase, $0.05 \mathrm{ml}$ of pancreatic deoxyribonuclease I solution (Io $\mathrm{mg} / \mathrm{ml}$; Koch-Light) was spread over the recipient culture on the transformation plates.

\section{RESULTS}

The nutritional requirements of Thermoactinomyces vulgaris. It soon became apparent that the organism would not grow appreciably on any one of several commonly used simple defined media. It was found that growth was rapid when vitamin-free acid-hydrolysed casein $(0.6 \%, \mathrm{w} / \mathrm{v})$ was added. Experiments with wild-type T9 were done to define its minimum nutritional requirements. When a synthetic mixture of 17 common L-amino acids (that is, excluding asparagine, glutamine and tryptophan, the latter being absent from acidhydrolysed casein) in equimolar quantities was added to Czapek-Dox medium instead of hydrolysed casein, significant growth occurred, although it was not nearly as luxurious as with hydrolysed casein. A series of tests was then done in which each amino acid in turn was omitted from the synthetic mixture; positive growth of the organism was recorded when isolated colonies on a streaked-out plate grew after $24 \mathrm{~h}$ incubation as well as they did on the complete synthetic mixture of amino acids. Amino acids that had no effect on growth were eliminated sequentially until all amino acids except six were eliminated: alanine, arginine, aspartic acid, methionine, threonine and valine. The optimal concentration of each of these amino acids was about I mM, but even at this concentration, growth was unsatisfactory.

To discover whether the superior growth-stimulating ability of hydrolysed casein was due to a specific factor, the material was run on a paper chromatogram and strips of the chromatogram were laid over plates of Czapek-Dox medium containing the six required amino acids, seeded with a dense suspension of Thermoactinomyces vulgaris spores. On incubation of the plates, a strong stimulation of growth occurred at a point with an $R_{\mathrm{f}}$ value of about 0.08 in the upper phase of a 4:1:5 mixture of $n$-butanol:acetic acid:water.

In an attempt to identify the unknown growth factor, several possible candidates were tested auxanographically, and it was found that spermidine was strongly stimulatory. The optimum concentration was determined as $0.0015 \%(\mathrm{v} / \mathrm{v})$. On the fully synthetic medium consisting of Czapek-Dox supplemented with the six amino acids and spermidine, growth was satisfactory for the detection of auxotrophic mutants in replicas from CM (Fig. I), and for the selection of recombinants from crosses, although it was not as rapid as on media containing hydrolysed casein.

Mutagenesis by heat. Chiasson \& Zamenhof (1966) described the induction of auxotrophic mutants of Bacillus subtilis by heating dry spores in vacuo; the mechanism of mutagenesis was presumably depurination of the DNA. Since the spores of Thermoactinomyces vulgaris resemble those of bacilli in structure and composition (Cross, I968, Cross, Walker \& Gould,

Fig. I. Recognition of auxotrophic mutants after mutagenesis by heating spores in vacuo at I I $5{ }^{\circ} \mathrm{C}$. A plate of colonies on complete medium (left) was replicated to fully synthetic minimal medium (right). After incubation for only $20 \mathrm{~h}$, most of the colonies on the replica are well grown and comparison of the two plates yields ten auxotrophic mutants (arrows) out of about 300 colonies.

Fig. 2. Selection of recombinants from mixed cultures. (a) I 278 thi-3 ura-I str-I $\times$ I 250 nic-I, selecting for $u r a^{+}$and str; note the total lack of parental background growth. (b) I 278 thi-3ura-I str-I $\times 1250$ nic-I, selecting $t h i^{+}$and str; note no background growth except where 'feeding' of the 1278 parent by thiamine occurs. (c) I 279 nic-I ura-I str-I $\times 1286 \mathrm{thi}-3$, selecting for $\mathrm{urd}^{+}$and $\mathrm{thi}^{+}$; note considerable syntrophic parental growth. 
Table 2. Mutagenesis by heating spores of strain 1227 in vacuo

The time of heating was $16 \mathrm{~min}$. Controls were unheated.

Two separate experiments are summarized.

\begin{tabular}{|c|c|c|c|c|}
\hline \multirow[b]{2}{*}{ Temperature } & \multirow{2}{*}{$\begin{array}{l}\text { Surviving } \\
\text { fraction }\end{array}$} & \multicolumn{2}{|c|}{ No. of colonies } & \multirow{2}{*}{$\begin{array}{c}\text { Auxotrophs } \\
(\%)\end{array}$} \\
\hline & & Total & Auxotrophs & \\
\hline $\begin{array}{l}\text { Control } \\
\text { I1 } 5^{\circ} \mathrm{C} \\
\text { I2I }{ }^{\circ} \mathrm{C}\end{array}$ & $\begin{array}{c}(1) \\
3 \times 10^{-3} \\
5 \times 10^{-6}\end{array}$ & $\begin{array}{r}\text { I } 108 \\
67 \mathrm{I} \\
154\end{array}$ & $\begin{array}{r}8 \\
36 \\
22\end{array}$ & $\begin{array}{c}0.7 \\
5.4 \\
14\end{array}$ \\
\hline $\begin{array}{l}\text { Control } \\
118^{\circ} \mathrm{C}\end{array}$ & $\begin{array}{c}(\mathrm{I}) \\
6 \times 10^{-3}\end{array}$ & $\begin{array}{r}1476 \\
747\end{array}$ & $\begin{array}{r}3 \\
59\end{array}$ & $\begin{array}{l}0.2 \\
7 \cdot 9\end{array}$ \\
\hline
\end{tabular}

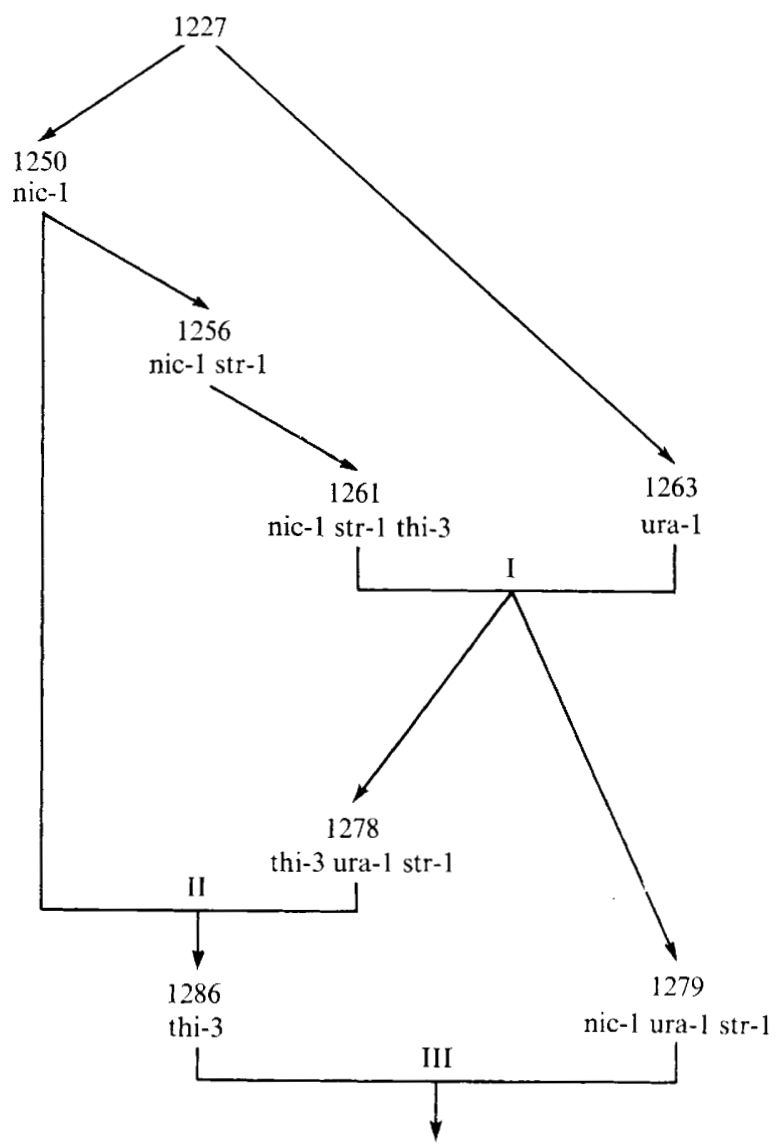

Fig. 3. Interrelations by mutation and recombination of the strains used to make crosses I, II and III (see Table 4).

I968; Dorokhova, Agre, Kalakoutskii \& Krassilnikov, I968), it was not unexpected that good yields of mutants were obtained also in this organism (Table 2). The proportion of auxotrophs amongst survivors increased with temperature up to at least I $2 \mathrm{I}{ }^{\circ} \mathrm{C}$. However, above this temperature, survival was very much reduced, being less than $10^{-7}$ at $125^{\circ}$. Thus I $2{ }^{\circ} \mathrm{C}$, or slightly above, was the highest practicable temperature. A wide spectrum of mutant 
Table 3. Results of crossing strains I 279 nic-I ura-I str-I and $\mathrm{I} 286$ thi-3

The cross was plated on each of the four selective media and a sample of about Ioo progeny from each medium was classified into their possible genotypes. The I 6 possible progeny genotypes are arranged in complementary pairs.

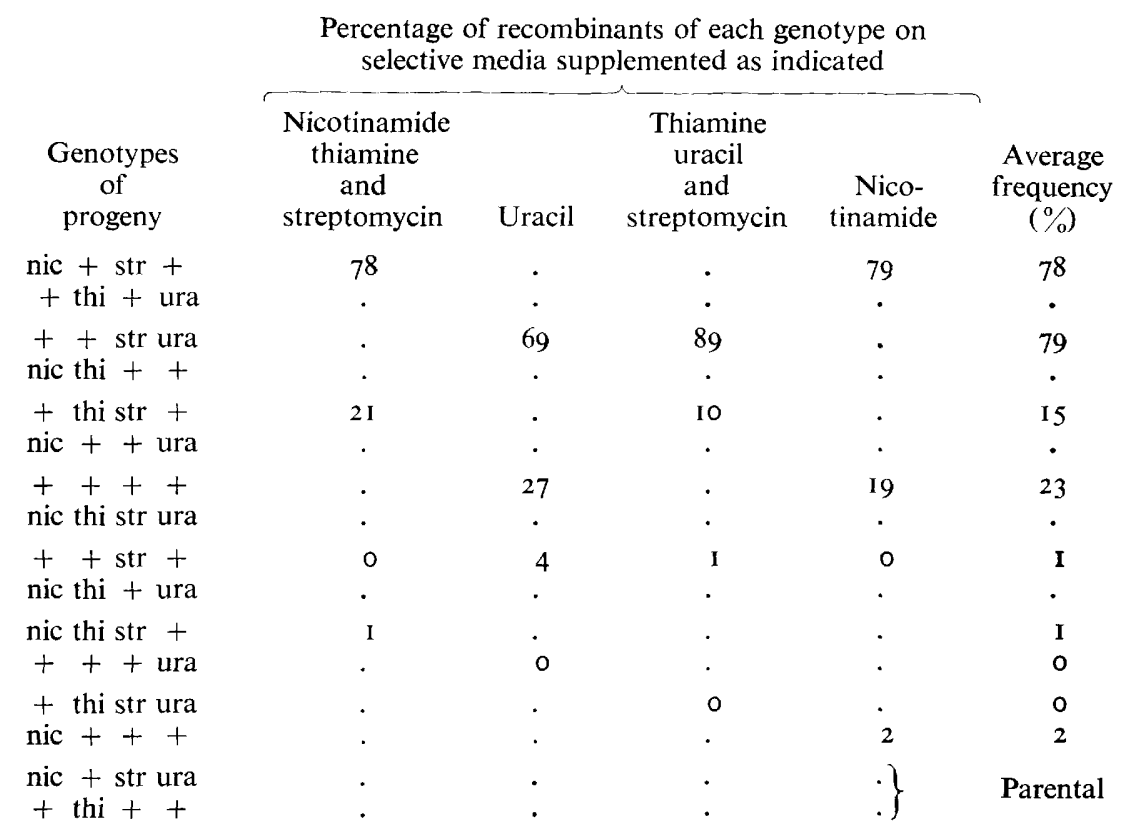

phenotypes was represented, including requirements for guanine, uracil, thymine, nicotinamide, thiamine, histidine, isoleucine, lysine, leucine, phenylalanine, proline, serine or tryptophan.

Ultraviolet light induced auxotrophs at much lower frequencies than heat, while $\mathrm{N}$ methyl- $N^{\prime}$-nitro- $N$-nitrosoguanidine, even under the extreme conditions of high $\mathrm{pH}$ and high concentration found effective for Streptomyces (Delić, Hopwood \& Friend, 1970), had no measurable effect on Thermoactinomyces vulgaris spores, presumably because they were impermeable to it.

Characteristics of recombination. Fig. 2 shows the appearance of selective plates on which spore suspensions derived from crosses were spread. It is obvious that the amount of 'background' growth due to spores of parental genotype varies considerably. In Fig. $2(a)$, where selection is for $u \mathrm{ra}^{+}$and $s t r$, no background occurs since streptomycin completely prevents growth of the streptomycin-sensitive parent, while the unsatisfied requirement for uracil hinders growth of the other parent. In Fig. $2(b)$, where selection is for $t h i^{+}$and str, there is some 'feeding' of the thiamine-requiring parent by the recombinant colonies, but relatively little background growth nevertheless occurs. In Fig. $2(c)$, on the other hand, where selection is for $\mathrm{ura}^{+}$and $t h i^{+}$and streptomycin is absent, syntrophic growth of both parents results in considerable background growth; however, the recombinant colonies can nevertheless be recognized with little ambiguity. In more extreme cases, syntrophic growth was too great to allow the unbiased recognition of recombinants, so that particular selections in certain crosses were precluded.

The results of a four-factor cross between derivatives of wild-type T9 have already been 
Table 4. Results of three four-factor crosses of Thermoactinomyces vulgaris $\mathrm{T} 9$ involving markers nic-I, thi-3, str-I and ura-I

The interrelationships of the parent strains are indicated in Fig. I. The I6 possible progeny genotypes are arranged in complementary pairs. Figures are their frequencies in arbitrary units (those for cross III are from Table 3 and those for cross I from Hopwood and Ferguson, 1970), based on samples of about 100 progeny from each selective medium in each cross. The top four pairs of progeny differ from one or other parent by a single marker; the bottom four pairs are either parental or differ from each parent by two markers.

\begin{tabular}{|c|c|c|c|}
\hline & & Crosses & \\
\hline & $\begin{array}{c}\text { I } \\
\text { nic thi str }+ \\
\times \\
+++ \text { ura }\end{array}$ & $\begin{array}{c}\text { II } \\
+ \text { thi str ura } \\
\times \\
\text { nic }+{ }^{+}+\end{array}$ & $\begin{array}{c}\text { III } \\
\text { nic }+ \text { str ura } \\
\times \\
+ \text { thi }++\end{array}$ \\
\hline nic + str + & 14 & Io & 78 \\
\hline+ thi + ura & . & $\cdot$ & $\cdot$ \\
\hline++ str ura & 73 & 83 & 79 \\
\hline nic thi ++ & $\cdot$ & $\cdot$ & $\cdot$ \\
\hline+ thi str + & I 5 & 79 & 15 \\
\hline nic ++ ura & . & $\cdot$ & $\cdot$ \\
\hline++++ & 94 & 24 & 23 \\
\hline nic thi str ura & $\cdot$ & $\cdot$ & $\cdot$ \\
\hline$++\operatorname{str}+$ & 0.5 & I & $\mathbf{I}$ \\
\hline nic thi + ura & $\cdot$ & $\cdot$ & $\cdot$ \\
\hline nic thi str + & Parental & 0.5 & $\mathbf{I}$ \\
\hline+++ ura & Parental & 0 & 0 \\
\hline+ thi str ura & I & Parental & 0 \\
\hline $\mathrm{nic}+++$ & 0 & Parental & 2 \\
\hline nic + str ura & I & 2 & Parental \\
\hline+ thi ++ & 0 & 0.5 & Parental \\
\hline
\end{tabular}

described (Hopwood \& Ferguson, 1970). As discussed by Hopwood (1959) in the context of Streptomyces coelicolor genetics, a set of three four-factor crosses involving the same markers in different coupling arrangements can be analysed selectively. The pair of strains that yielded the first data were derived from the wild-type by successive mutation. Recombinants isolated from this and subsequent crosses allowed the set of three crosses to be performed. The interrelations of the six strains are in Fig. 3.

Each cross was studied by plating its products on a set of four selective media; each medium selected, in turn, one of the two selectable markers from one parent in combination with either of the two selectable markers from the other, the remaining two markers on each medium being non-selected. In this way, nine of the 16 possible genotypes of progeny could be recovered. (See Table 3.)

The data of the three crosses are summarized in Table 4. The striking feature of these data is that the same four selectable recombinant classes had high frequencies in each cross, while the remaining classes had very much lower frequencies. The common classes were those that differed from one parent or the other in respect of a single marker, while the rare classes differed from both parents by two markers. This result indicates that the process of genetic transfer is such that only small fractions of the total genome of one strain are transferred to the other: when a selected marker is transferred, it is only rarely accompanied by a second, non-selected marker. This feature is characteristic of genetic transfer by transformation or transduction.

A consistent feature of the Table 4 data is that the frequencies of the four common progeny 
Table 5. Effect of deoxyribonuclease (DNase) on recombination frequency

The parents were I26I (nic-I thi-3 str-I) and 1336 (trp-2). Mixed cultures were incubated $22 \mathrm{~h}$ at $52{ }^{\circ} \mathrm{C}$. DNase concentration was $15 \mu \mathrm{g} / \mathrm{ml}$ of agar medium.

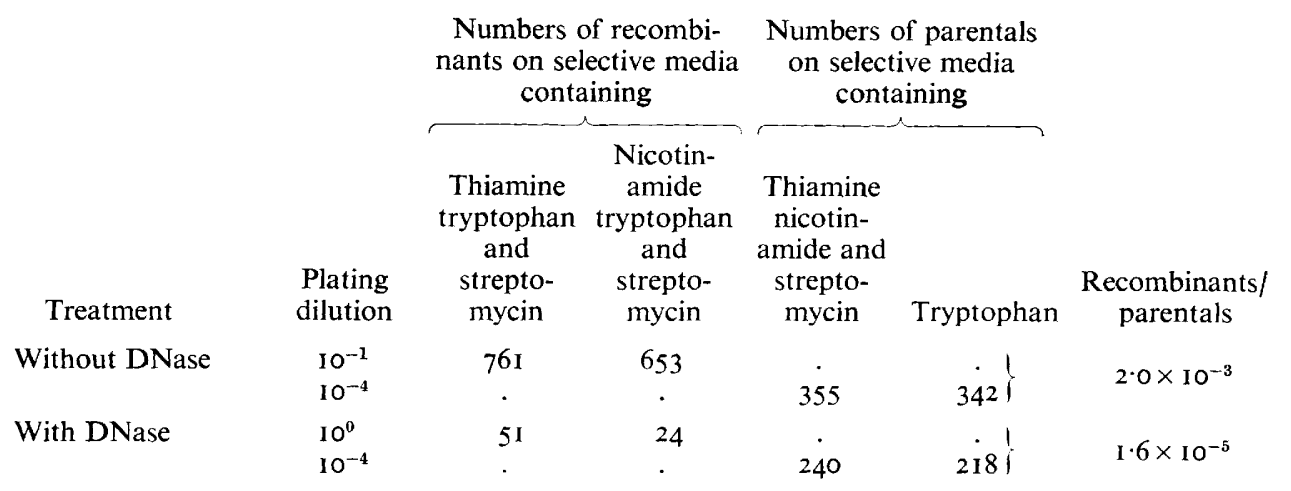

Table 6. Lack of effect of DNase on the relative frequencies of different classes of recombinants in a cross of strains $\mathrm{I} 279$ (nic-I ura-I str-I) and I 286 (thi-3)

\begin{tabular}{|c|c|c|c|c|c|c|}
\hline \multirow{3}{*}{$\begin{array}{l}\text { Recombinant } \\
\text { genotypes }\end{array}$} & \multicolumn{6}{|c|}{$\begin{array}{c}\text { Numbers of recombinants of each genotype in samples from } \\
\text { selective media supplemented as indicated }\end{array}$} \\
\hline & \multicolumn{2}{|c|}{$\begin{array}{l}\text { Nicotinamide thiamine } \\
\text { and streptomycin }\end{array}$} & \multicolumn{2}{|c|}{$\begin{array}{l}\text { Thiamine uracil and } \\
\text { streptomycin }\end{array}$} & \multicolumn{2}{|c|}{ Nicotinamide } \\
\hline & - DNase & + DNase & -DNase & + DNase & -DNase & + DNase \\
\hline $\mathrm{nic}+\mathrm{str}+$ & 82 & 63 & . & . & 71 & 84 \\
\hline++ str ura & $\cdot$ & $\cdot$ & 89 & 77 & . & $\cdot$ \\
\hline+ thi str + & 13 & 15 & 4 & 13 & . & . \\
\hline++++ & . & . & . & . & 7 & 12 \\
\hline$++\operatorname{str}+$ & I & 3 & 3 & 0 & I & I \\
\hline nic thi str + & 0 & I & . & . & . & . \\
\hline+ thi str ura & . & . & 0 & 0 & . & . \\
\hline $\mathrm{nic}+++$ & . & . & $\cdot$ & $\cdot$ & 0 & 0 \\
\hline Totals & 96 & 82 & 96 & 90 & 79 & 97 \\
\hline
\end{tabular}

classes occur in pairs in each cross: two high and two lower. The pattern is compatible with the notion of transfer of single markers from strain to strain, with one parent in each cross behaving more often as recipient than as donor. For example, in cross I nic str (frequency I4) and thi str (I5) occur when the nic thi str parent acts as recipient, while str ura (73) and the fully wild-type class (94) are produced when the ura parent is recipient.

\section{Effect of deoxyribonuclease on recombination}

A unique characteristic of genetic transfer by transformation is its sensitivity to deoxyribonuclease (DNase). In order to test the possibility that DNase might prevent or reduce recombination in Thermoactinomyces vulgaris, crosses were made on slants of CM containing I $5 \mu \mathrm{g} / \mathrm{ml}$ DNase. After incubation of the mixed cultures for $24 \mathrm{~h}$, spores were harvested in the normal way and plated on one or more media selective for recombinants, and on the two media each selecting one of the parental phenotypes. Control crosses without DNase were analysed at the same time. An example is given in Table 5, in which we see that DNase 
reduced the frequency of recombination from $2 \times 10^{-3}$ to $1 \cdot 6 \times 10^{-5}$, a 120 -fold reduction. This result indicated that at least part of the genetic transfer occurring in mixed cultures of $T$. vulgaris strains was sensitive to DNase, and so was presumably due to transformation.

The few recombinants recovered from mixed cultures grown in the presence of DNase could have resulted from transformation which escaped the action of the enzyme; alternatively, a second, DNase-resistant mode of genetic transfer might conceivably have occurred at low frequency. The experiment summarized in Table 6 shows that the relative frequencies of different genotypes were the same amongst recombinants arising after growth of the cross in the presence or absence of DNase. In particular, the classes differing from both parents by two markers, which as we saw above (Tables 3,4) were rare amongst the total progeny, were equally rare amongst the recombinants surviving DNase treatment. If a second mode of transfer had involved the passage of large segments of genetic material from strain to strain, as a conjugation process would have been expected to do, then the genotypes differing from both parents by two markers should have had a higher frequency after DNase treatment. The simpler hypothesis is that the DNase treatment was incompletely effective in destroying extracellular tranforming DNA.

The demonstration of transformation. It was found that DNA prepared from a culture of wild-type T9 by a simplified version of the procedure of Marmur (I96I), as described in Methods, was very effective in transforming a recipient culture in respect of auxotrophic markers. We have so far been unable to eliminate viable spores completely from the DNA solution; after several deproteinizations by shaking with chloroform, DNA preparations typically contained ro to Ioo viable spores per ml. Even after shaking with phenol, or after centrifuging the DNA solution at $10000 \mathrm{rev} / \mathrm{min}$ for Io min (Marmur, 1961), a few viable spores remained. In order to eliminate any possible confusion from viable spores in samples of transforming DNA, streptomycin-resistant strains were used exclusively as recipients and streptomycin-sensitive strains as donors; transformations were carried out on streptomycincontaining media.

As described in Methods, transformation was tested by a two-stage procedure; donor DNA and recipient spores were incubated together on a medium on which the recipient strain could grow, and when the culture had sporulated, spores were harvested and plated on media selective for recombinants. An experiment illustrating the occurrence of transformation and its elimination by DNase is illustrated in Fig. 4.

The relationship between DNA concentration and the frequency of transformants (that is the ratio of transformants to progeny of recipient genotype) in respect of two markers is shown in Fig. 5. As in other systems, there is a logarithmic relationship between transformation frequency and the amount of transforming DNA over a considerable range; saturation was not reached in these experiments. The ratio of transformation for the two markers in Fig. 5 was the maximum so far found; the frequency of transformation for several other markers fell within the range demonstrated by nic-I and thi-3.

The effect on transformation frequencies of the concentration of recipient spores on the transformation plates was tested by plating $10^{4}, \mathrm{IO}^{5}, \mathrm{I}^{6}$ or $10^{7}$ spores with a constant amount of DNA. It was found that the transformation frequency was essentially the same at plating densities of $10^{5}$ or above, all of which led to confluent mycelial growth. At $10^{4}$ spores per plate, which led to discrete colonies rather than confluent growth, the transformation frequency was considerably reduced. The independence of transformation frequency on spore density above this low threshold value was a practical convenience.

As expected for genetic transfer mediated by transformation, the great majority of recombinants inherited single markers from the donor. A number of experiments were 


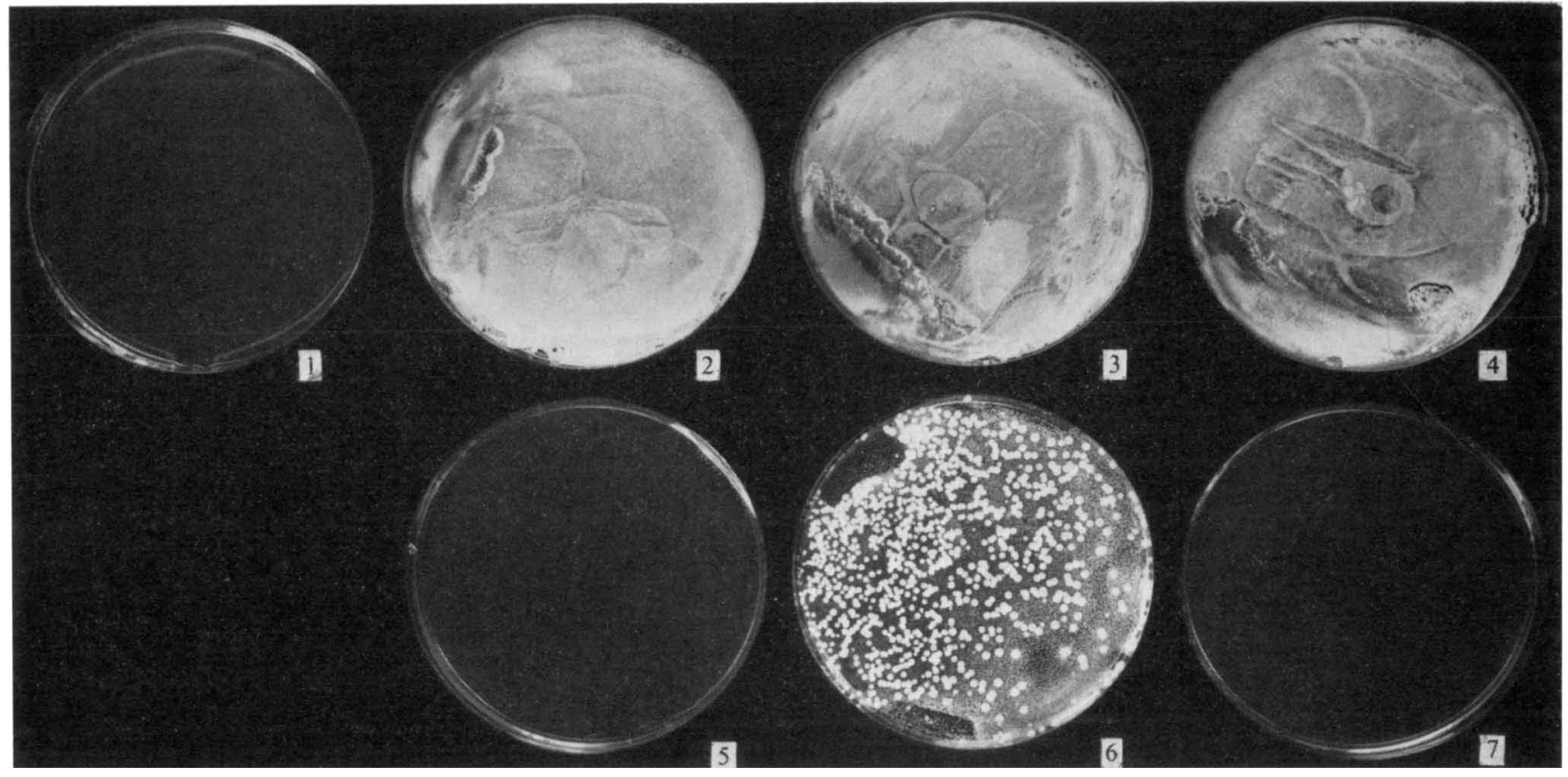

+ Nicotinamide

(non-selective)

Fig. 4. Transformation and its elimination by DNase. Plates I to 4 contained nicotinamide, thiamine and streptomycin (non-selective for the recipient). Plates 5 to 7 contained thiamine and streptomycin but lacked nicotinamide and were thus selective for $n_{i c} c^{+}$colonies. Plates $\mathrm{I}, 3$ and 4 were spread with a solution containing Ioo $\mu \mathrm{g}$ of T9 DNA plates 2 to 4 with a spore suspension of recipient strain Plates $\mathrm{I}, 3$ and 4 were spread with a solution containing Ioo $\mu \mathrm{g}$ of T9 DNA plates 2 to 4 with a spore suspension of recipient strain
I 26I nic-I thi-3 str-I, and plate 4 also with a solution containing $50 \mu \mathrm{g}$ of DNase. After incubation of plates I to 4 spores from plates 2 to 4 were spread on plates 5 to 7 respectively. Note the lack of $n i c^{+}$colonies on plate 5 ('recipient only control') and plate 7 ('DNase control') and the presence of numerous nic ${ }^{+}$transformations on plate 6 . 


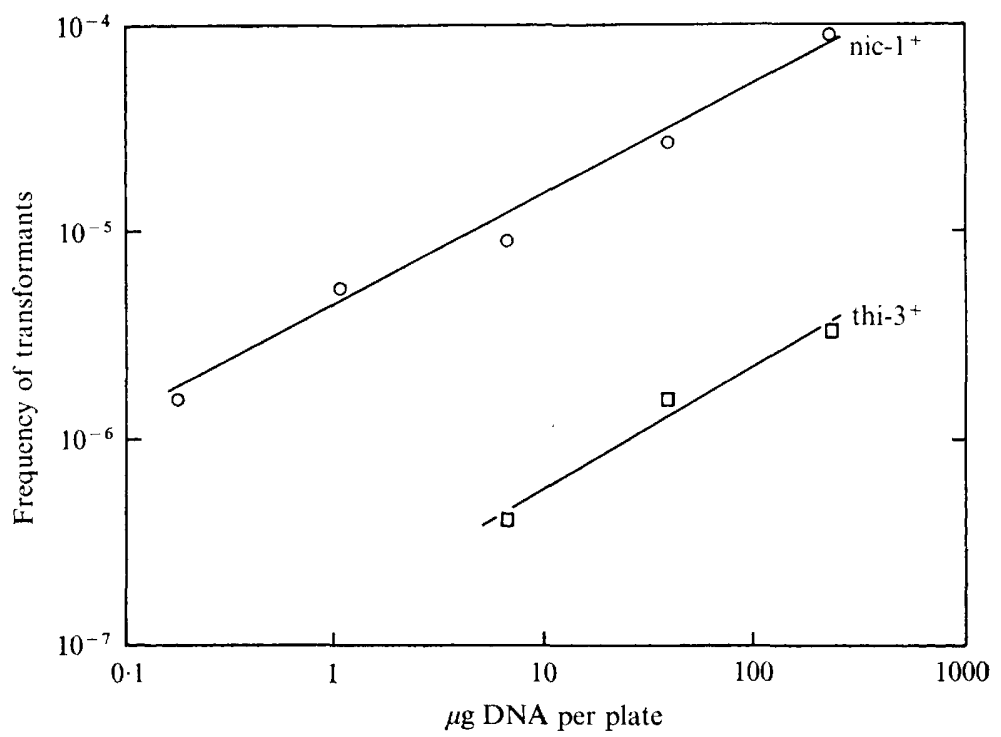

Fig. 5. Relationship between transformation for two markers in strain I 261 nic-I thi-3str-I and the amount of T9 DNA added to the transformation plate.

Table 7. Development of competence by strain $\mathbf{1 2 6 \mathrm { I }}$

Three experiments are reported: (I) DNA added to a growing recipient culture at different times; (2) DNA added at zero time and DNase added at different times; (3) DNA added at different times, following by DNase $30 \mathrm{~min}$ later. In each experiment, I20 $\mu \mathrm{g}$ DNA was added to each plate; the DNA was from separate preparations, probably accounting for the higher specific transformation in experiment (2).

( I)

$\begin{array}{cc}\begin{array}{c}\text { Time of adding } \\ \text { DNA (h) }\end{array} & \begin{array}{c}\text { ic }^{+} \\ \text {transformants } \\ \text { per } 10^{6}\end{array} \\ 0 & 36 \\ 2.5 & 48 \\ 5 & 43 \\ 7.5 & 93\end{array}$

(2)

$\begin{array}{cc}\begin{array}{c}\text { Time of adding } \\ \text { DNase (DNA } \\ \text { added at o h) }\end{array} & \begin{array}{c}\text { nic }^{+} \\ \text {transformants } \\ \text { per } 10^{6}\end{array} \\ \text { o to } 8 & 0^{*} \\ 9 & 5.2 \\ \text { I0.5 } & 380 \\ \text { I } 4.75 & 2700 \\ \text { No DNase } & 650\end{array}$

(3)

$\begin{array}{cc}\text { Time of adding } & \\ \begin{array}{c}\text { DNA (DNase } \\ \text { added } 30 \text { min } \\ \text { later) }\end{array} & \begin{array}{c}\text { nic }^{+} \\ \text {transformants } \\ \text { per } 10^{6}\end{array} \\ \text { o to } 6 & 0^{*} \\ 7 & 3.4 \\ 8 & 29 \\ 9 & 58 \\ \text { 10 } & 63\end{array}$

* The experiment would have detected a frequency of about 0.01 per $10^{6}$.

performed to try to detect an enhanced co-transformation of particular pairs of markers that would have indicated linkage. In one experimental design, a number of mutant derivatives of strain 1332 nic-I thi-3 pro- $I$ str-I, each carrying a different additional auxotrophic mutation, were transformed by wild-type DNA and selection was made alternatively for inheritance of nic- $\mathrm{I}^{+}$, thi $-3^{+}$or pro- $\mathrm{I}^{+}$from the donor on suitably supplemented MMS, with the additional marker non-selected. The plates of colonies arising were then replicated to media testing for the inheritance of the additional donor marker. The frequency of cotransformation was in all cases within the range 0.01 to $1 \%$, indicating a lack of detectable linkage of each new marker with nic-I, thi-3or pro-I. Similar conclusions derived from experiments in which primary selection was made separately for each of two donor markers and for co-transfer of the two markers. 
Competence. In the first transformation experiments, DNA was added to the recipient culture either before incubation was begun, or after varying periods of incubation up to $7.5 \mathrm{~h}$, by which time considerable mycelial growth of the organism had taken place. The frequency of transformants varied little (Table 7, column I). This result indicated either that the recipient culture was competent at all times, or that the added DNA remained active until being taken up at the time when competence developed. Further experiments of two kinds indicated the latter interpretation to be correct.

In the first group of experiments, DNA was added to the recipient spores at the time of plating and, after various periods of incubation, DNase was added to the growing culture. The culture was then harvested and assayed for transformants after incubation for a total period of $24 \mathrm{~h}$. It was found that, when DNase was added during the first 6 to $8 \mathrm{~h}$ (depending on the experiment), no transformants were detected; only if growth occurred for at least 7 to $9 \mathrm{~h}$ before addition of DNase did transformants begin to appear in the mature culture and soon reached a high frequency. An example is given in Table 7, column (2).

In the second type of experiment, DNA was added to the recipient culture after various periods of incubation, and DNase was added 30 min after the addition of the DNA. An example is given in Table 7, column (3). These results agree with those of the previous type of experiment in showing that DNA is not taken up by a growing culture during the first several hours of incubation (at least $6 \mathrm{~h}$ in this example) and that maximum yields of transformants are obtained within a few hours of the onset of competence.

Variation by a few hours in the onset of competence in different experiments was not unexpected in view of the obvious variation in the growth rate that occurred in different experiments, perhaps due to the different physiological condition of the spores in the inoculum, or to slight differences in the medium. Although no precise correlation of the development of competence with the stage of differentiation of the culture has yet been attempted, it appeared that competence occurred at or immediately before the beginning of the development of aerial mycelium and so of spores.

Crosses involving other wild-types. The results so far described concern a single wild-type, T9. Some studies were also made of other newly isolated wild-type strains designated TI, T2, etc., as well as strain CUB76. Auxotrophic mutants of several of these strains were isolated, and streptomycin-resistant mutants of some of the auxotrophs; this enabled crosses to be attempted between mutant derivatives of a particular wild-type and the parental strain, as well as between derivatives of different wild-types, by growing mixtures of pairs of strains on non-selective medium and plating the resulting spores on selective media.

The results indicated that most wild-types resembled T9 in being self-fertile; they were also fertile with each other and in such crosses the pattern of marker segregation showed that both parents were functioning as donors in the origin of some recombinant progeny and as recipients in the origin of others. The evidence for this conclusion was that fourfactor crosses yielded data of the type already summarized in Table 3; that is, all four classes differing from each parent by a single marker, two from one and two from the other, had appreciable frequencies, and all other classes had very low frequencies. T5 and T8 were examples of this kind of strain. Their competence was confirmed by the demonstration that they could be transformed with T9 DNA.

There remained certain wild-types, exemplified by $\mathrm{T} 3$ and $\mathrm{CUB} 76$, which were self-sterile and also sterile in mixed culture with each other; $5 \times 10^{8}$ or more spores from mixed cultures of a wild-type and a streptomycin-resistant auxotrophic mutant yielded no colonies on MM containing streptomycin. However, when these wild-types, or their mutant derivatives, were crossed with derivatives of the self-fertile class of wild-types ( $\mathrm{T} 5, \mathrm{~T} 8, \mathrm{~T} 9$ ), recombinants 
Table 8. Results of crossing strain 126I nic-I thi-3 str-I with CUB76 trp

\begin{tabular}{|c|c|c|c|c|c|}
\hline \multirow[b]{2}{*}{$\begin{array}{c}\text { Genotypes } \\
\text { of } \\
\text { progeny }\end{array}$} & \multicolumn{4}{|c|}{$\begin{array}{l}\text { Recombinants of each genotype on selective media } \\
\text { supplemented as indicated }\end{array}$} & \multirow[b]{2}{*}{$\begin{array}{c}\text { Average } \\
\text { frequency }(\%)\end{array}$} \\
\hline & $\begin{array}{l}\text { Nicotinamide } \\
\text { tryptophan } \\
\text { streptomycin }\end{array}$ & Thiamine & $\begin{array}{l}\text { Thiamine } \\
\text { tryptophan } \\
\text { streptomycin }\end{array}$ & Nicotinamide & \\
\hline nic str ++ & 554 & • & $\cdot$ & 544 & 99 \\
\hline+ str thi + & ד & 538 & $54 \mathrm{I}$ & 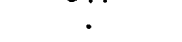 & 99 \\
\hline$+\operatorname{str}+\operatorname{trp}$ & 0 & . & 0 & . & 0 \\
\hline++++ & . & 0 & . & 0 & 0 \\
\hline$+\operatorname{str}++$ & I & 4 & 2 & 0 & 0.3 \\
\hline nic str $+\operatorname{trp}$ & 3 & . & . & . & 0.5 \\
\hline++ thi + & . & 5 & . & . & 0.9 \\
\hline+ str thi trp & . & . & 3 & . & 0.5 \\
\hline $\mathrm{nic}+++$ & . & . & . & 5 & 0.9 \\
\hline Totals & 558 & 547 & 546 & 549 & \\
\hline
\end{tabular}

arose with frequencies (e.g. $3 \times 10^{-5}$ ) within the range yielded by homologous crosses $(\mathrm{T} 9 \times$ T9, etc.). When four-factor crosses were analysed the pattern of marker segregation differed markedly from that in homologous crosses. For example, in a cross of a nic thi str derivative of T9 with a trp mutant of CUB76 (Table 8), the two classes differing from the T9 strain by a single marker (nic str ++ and + str thi + ) were very common, whereas those differing from the CuB 76 strain by one marker $(+s t r+\operatorname{tr} p$ and ++++ ) had unmeasurably low frequencies lower than those of the five classes differing from the T9 parent by two markers.

These findings taken together indicated that strains of the class represented by $\mathrm{T} 5, \mathrm{~T} 8$ and T9 were competent in transformation, whereas T3 and CUB76 were incompetent as recipients but nevertheless were able to function as donors.

\section{DISCUSSION}

The discovery of transformation in Thermoactinomyces vulgaris, as described in this paper, represents the first well-documented example of typical transformation in an actinomycete. There have been previous claims of transformation in members of the genus Streptomyces, but the earlier ones, as discussed by Sermonti \& Hopwood (I964), were based on preliminary experimental data and they have yet to be confirmed. A recent report (Biswas \& Sen, I97I) described studies of strains differing in antibiotic production rather than in typical auxotrophic or resistance characters. On the other hand, recombination by some kind of cellular contact ('conjugation') has now been discovered in several streptomycetes (Sermonti \& Hopwood, 1964; Hopwood, 1967; Sermonti, 1969; Alačević, 1970; Coats \& Roeser, 197I ; Friend \& Hopwood, 197I) as well as members of the genera Nocardia (Adams, 1964) and Micromonospora (Beretta, Betti \& Polsinelli, I97I).

Transformation is, of course, not ideal as a tool in general genetic analysis since, in its simple form, it is not suited to long-range mapping nor to studies of complementation and dominance. However, transformation lends itself readily to studies of genetic fine structure such as may be needed in the analysis of spore antigens or the heat tolerance of enzymes.

This study underlines the relevance of certain practical considerations in the search for genetic recombination in a new bacterium. The first concerns the use of other wild-types if recombination is not found in a particular strain. In this study the first wild-type happened 
to belong to a group of incompetent, self-sterile strains; success followed from the study of other wild-types, some of which were competent and therefore self-fertile. Self-fertile and self-sterile wild-types are, of course, already familiar in bacteria such as Escherichia coli in which only sex-factor-carrying strains can transfer their chromosome by conjugation; in transformation systems, incompetent wild-types or mutants are also known in other bacteria (Jyssum \& Lie, 1965; and references in Tomasz, 1969).

A second consideration is the design of experiments intended to reveal recombination. The particular kind of cross described here, involving parents differing by four selectable markers analysed by plating on four different selective media, was first applied in Streptomyces coelicolor (Hopwood, I959) and has recently been used successfully in S. rimosus (Friend \& Hopwood, I97I) and S. bikiniensis (Coats \& Roeser, 197I). In these streptomycetes, in which comparatively large segments of genetic material are transferred by 'conjugation', this method of analysis serves as a mapping procedure. In Thermoactinomyces vulgaris, in which small segments of genetic material are transferred by transformation, simple mapping by this technique was impossible; however, an advantage of this method of analysis was that it clearly revealed the transfer to be fragmentary (Hopwood \& Ferguson, I970).

Relevant to the significance of transformation in natural populations of bacteria is the comparatively high rate of recombination that occurs in mixed cultures of Thermoactinomyces vulgaris, approaching $\mathrm{IO}^{-3}$ for particular markers. Such 'spontaneous' transformation has previously been reported in other systems such as Bacillus subtilis (Takahashi, I962; Ephrati-Elizur, I968) and pneumococcus (Ottolenghi \& Hotchkiss, I960). High frequencies of transformation in mixed cultures of $T$. vulgaris imply the absence of significant extracellular deoxyribonuclease activity. This is also indicated by the fact that DNA added to a young mycelial culture remains biologically active for several hours before finally being taken up by the culture when it becomes competent. A practical advantage of this state of affairs is that the experimental attainment of competence is not a problem;donor DNA can simply be plated with enough recipient spores to give confluent growth on non-selective medium and incubated until recombinant progeny have been produced, which are subsequently detected by replating on selective media. This system does not obviously fulfil the requirements for accurate quantitation, the most important of which is the avoidance of differential multiplication of recombinant genotypes after their production (Hotchkiss, I957), and may have to be modified when precise genetic analysis is undertaken. However, the finding of a simple relationship between transformation frequency and DNA concentration (Fig. 5) or inactivation of the DNA" by mutagenic treatments (D. A. Hopwood \& H. M. Wright unpublished results), suggests that quantitation may be better than might be expected at first sight; conceivably DNA is taken up by sporangia each of which gives rise to a single spore rather than undergoing further reproduction.

Little can be said about competence in this system beyond the simple finding that its onset occurred at about the time that sporulation was initiated. A deeper study of competence in this mycelial organism might be interesting for comparison with the morphologically simpler eubacteria (Tomasz, I969).

\section{REFERENCES}

Adams, J. N. (1964). Recombination between Nocardia erythropolis and Nocardia canicruria. Journal of Bacteriology 58, 865-876.

AlačEvić, M. (1970). Genetics of tetracycline producing streptomycetes. Abstracts of the First International Symposium on Genetics of Industrial Microorganisms, Prague, pp. 44-45. 
Beretta, M., Betti, M. \& Polsinelli, M. (1971). Genetic recombination in Micromonospora. Journal of Bacteriology 107, 415-419.

Biswas, G. D. \& SEN, S. P. (I97I). Transformation in Streptomyces with respect to antibiotic production. Journal of Applied Bacteriology 34, 287-293.

Chiasson, L. P. \& Zamenhof, S. (1966). Studies on induction of mutations by heat in spores of Bacillus subtilis. Canadian Journal of Microbiology 12, 43-46.

COATS, J. H. \& ROESER, J. (1971). Genetic recombination in Streptomyces bikiniensis var. zorbonensis. Journal of Bacteriology 105, 880-885.

Cross, T. (1968). Thermophilic actinomycetes. Journal of Applied Bacteriology 31, 36-53.

Cross, T., WALKER, P. D. \& GouLD, G.W. (1968). Thermophilic actinomycetes producing resistant endospores. Nature, London 220, 352-354.

Delić, V., Hopwood, D. A. \& FrIEND, E. J. (1970). Mutagenesis by $N$-methyl- $N^{\prime}$-nitro- $N$-nitrosoguanidine (NTG) in Streptomyces coelicolor. Mutation Research 9, I67-182.

Dorokhova, L. A., Agre, N. S., Kalakoutskit, L. V. \& Krassilnikov, N. A. (I968). Fine structure of spores in a thermophilic actinomycete, Micromonospora vulgaris. Journal of General and Applied Microbiology 14, 295-303.

Ephrati-Elizur, E. (1968). Spontaneous transformation in Bacillus subtilis. Genetical Research 11, 83-96.

Friend, E. J. \& Hopwood, D. A. (197I). The linkage map of Streptomyces rimosus. Journal of General Microbiology 68, 187-I97.

Hopwood, D. A. (1959). Linkage and the mechanism of recombination in Streptomyces coelicolor. Annals of the New York Academy of Sciences 81, 887-898.

Hopwood, D. A. (1967). Genetic analysis and genome structure in Streptomyces coelicolor. Bacteriological Reviews 3r, 373-403.

Hopwoon, D. A. \& Ferguson, H. M. (1970). Genetic recombination in a thermophilic actinomycete, Thermoactinomyces vulgaris. Journal of General Microbiology 63, I33-I 36.

HopwOOD, D. A. \& WRIGHT, H. M. (I97I). Genetic transformation in a thermophilic actinomycete. Heredity 27, 483.

Hotchkiss, R. D. (1957). Criteria for quantitative genetic transformation of bacteria. In The Chemical Basis of Heredity, pp. 32I-335. Edited by W. D. McElroy \& B. Glass. Baltimore: Johns Hopkins Press.

JysSUM, K. \& LIE, S. (1965). Genetic factors determining competence in transformation of Neisseria meningitidis. Acta pathologica et microbiologica scandinavica 63, 306-316.

MARMUR, J. (196I). A procedure for the isolation of deoxyribonucleic acid from micro-organisms. Journal of Molecular Biology 3, 208-21 8.

MCVITTIE, A. C., Wildermuth, H. \& Hopwood, D. A. (1972). Fine structure and surface topography of Thermoactinomyces vulgaris endospores. Journal of General Microbiology 7r, 367-38I.

OTTOLENGHI, E. \& HotchKIS, R. D. (1960). Appearance of genetic transforming activity in pneumococcal cultures. Science, New York 132, I257-1 258.

Pepys, J., Jenkins, P. A., Festenstein, G. N., Gregory, P. H., Lacey, M. E. \& Skinner, F. A. (I963). Farmer's Lung. Thermophilic actinomycetes as a source of 'farmer's lung hay' antigen. Lancet ii, 607-6II.

SERMONTI, G. (1969). Genetics of Antibiotic-producing Micro-organisms, pp. 303-310. London: WileyInterscience.

Sermonti, G. \& Hopwood, D. A. (1964). Genetic recombination in Streptomyces. In The Bacteria, vol. 5, pp. 223-25I. Edited by I. C. Gunsalus and R. Y. Stanier. New York: Academic Press.

Silvestri, L. G. (1970). The evolution of the thermophilic Actinomycetales: An apparent evolutionary paradox. In The Actinomycetales, the Jena International Symposium on Taxonomy, 1968, pp. 239-243. Edited by H. Prauser: Jena: Gustav Fischer Verlag.

StReIPS, U. N. \& WelKer, N. E. (197I). Factors affecting transfection in Bacillus stearothermophilus. Journal of Bacteriology 106, 960-965.

TAKAHASHI, I. (1962). Genetic transformation of Bacillus subtilis by extracellular DNA. Biochemical and Biophysical Research Communications 7, 467-470.

Tomasz, A. (1969). Some aspects of the competent state in genetic transformation. Annual Reviews of Genetics 3, 217-232. 